Research Article

\title{
Innovative Ways to Teach Mathematics: Are they Employed in Schools?
}

\author{
Yousef Methkal Abd ALGANI*1(D) \\ ${ }^{1}$ Sakhnin College, Department of Mathematics, Israel, yosefabdalgani@gmail.com \\ * Corresponding Author: yosefabdalgani@gmail.com
}

\begin{tabular}{|c|}
\hline Article Info \\
\hline $\begin{array}{l}\text { Received: } 28 \text { August } 2019 \\
\text { Accepted: } 16 \text { October } 2019\end{array}$ \\
\hline $\begin{array}{l}\text { Keywords: Teaching mathematics, } \\
\text { Conceptual method, Innovative } \\
\text { method. }\end{array}$ \\
\hline
\end{tabular}

DOI: 10.18009/jcer.612199

Publication Language: English \begin{abstract}
This study sheds light on the various strategies to teach mathematics and whether they are employed or not. The study investigates the employed mathematics-teaching strategies in Arab schools in northern Israel, and the hindrances that prevent teachers from applying diverse effective strategies in their classrooms. The researcher follows the qualitative approach based on in-depth interviews and recommendations of previous studies and observation to obtain the maximum benefits and give accurate qualitative results based on interviews, from Arab schools in northern Israel who study in six different schools. Teachers assert that employing the different innovative strategies are vital and efficient in teaching mathematics, but there are many handicaps that prevent teachers from exploiting them including, amongst others, the imposed duties to complete the entire amount of loaded study material during the semester, as well as the lack of available tools to computerize classes and teaching process in general, the lack of building tangible tools, and the low proficiency level of some teachers. The results of the interviews showed that technology is rarely employed in teaching mathematics - if ever, as well as innovative and modern strategies. The study concludes that the heavy burden of teaching mathematics should be lightened to allow space for creativity in teaching strategies, as they need more time to be employed. In addition, for mathematics to be understood properly, the teaching process should be interesting to attract students. Besides this, the suggested strategies are advantageous to be applied in the teaching process.
\end{abstract}

To cite this article: Algani, Y.M.A. (2019). Innovative ways to teach mathematics: are they employed in schools?. Journal of Computer and Education Research, 7 (14), 496-514. DOI: 10.18009/jcer.612199

\section{Introduction}

The role of education nowadays is undeniable. It is the driving force that moves society from the state of inertia and slow growth to the rapid movement of progress and development in economic and human resources. Education is an issue of national security and the first line of defense against the dangers and disadvantages of globalization. It is also the basic tool for the investment of human resources, which is now the main basis for economic progress and globalization (Algani, 2018). 
Science and knowledge are the main basis for any development, so they should be a priority for all countries in order to cope with the massive technological development that the globe currently witnesses. Mathematics is an integral part of science; in fact, it is the core component of science. If we understand its importance and the critical role of its applications in life, we can use it in the right ways that will contribute to the scientific and technical progress of our nation. However, the fact that the vast majority of students consider it a difficult subject to learn makes it urgent for schools to exploit all resources and strategies to help students understand it (Algani, 2018).

Unfortunately, the findings of the latest Meitzav tests 1 in the schools in which the research will be held, indicate low achievements in mathematics and in the sciences (around $40 \%$ ) both in comparison with the results at the level of the Arab sector as a minority population and at the national level. In addition, the findings show that in the questionnaire which examined the position of school pupils towards the two subjects, about $80 \%$ of the pupils in Grade 8 gave higher importance to the study of the two subjects, although only an average of $55 \%$ reported that they enjoyed learning sciences and mathematics. It should be remembered that only a small percentage of the pupils who continued their studies in high schools are studying in the science track, and most of them study mathematics at the 3-unit level (National authority for measurement and evaluation in education in Israel-RAMA, 2018).

Thus, all available means should be employed to improve teaching all materials, especially mathematics. Furthermore, some important obstacles stand in the face of employing effective strategies in teaching mathematics in schools, which are manifested mainly in the burden of completing the entire loaded study material of the textbook. This way, the ultimate objective would be to manage teaching the entire textbook in one semester at the expense of employing various strategies while teaching. Moreover, teachers would have to build upon the material taught by the previous teachers because mathematics is a

\footnotetext{
${ }^{1}$ Meitav (Measure of Efficiency and School Growth) is a system of tests and surveys conducted in elementary and intermediate schools in Israel. The tests are held in the subjects of Science and Technology, the native language (Hebrew or Arabic), Mathematics and English. The surveys are conducted among the pupils, teachers, and principals, and deal with a long list of subjects that reflect the social and pedagogical climate in the school. The tests and surveys are held annually in a third of the schools, so that every school participates in Meitav once every three years. The tests and surveys are conducted by RAMA (National Authority for Measurement and Evaluation in Education).
} 
cumulative science. Nonetheless, if the previous teacher was not good enough, a critical problem arises; the current teacher would have to explain the material that the student did not understand in order to be able to explain the new material, which would be time consuming amongst other things.

Teachers should pay careful attention to the strategies applied in teaching mathematics after taking into consideration the existing obstacles, the needs of students, and the objectives that have to be to fulfilled, since "teaching strategies are tools that the teacher uses to achieve the objectives, mainly the intellectual development of the student (Enríquez et al., 2018, p.115). By the same token, the statement of Entwistl (2005) which is cited in Enríquez et al., (2018: 115), is that: It is essential, for the teacher, to pay attention not only to the topics that must be included in the programs and that should be addressed in class, but also, and simultaneously, in the manner in which it can be considered more convenient for those topics to be worked on by the students. The relationship between themes and the way to approach them is so strong that it can be argued that both themes and didactic treatment strategies are inseparable. It is evident that the way the material is presented and explained affects the students' understanding and their attraction to mathematics. This urges teachers to employ various strategies that have proved to be efficient and to employ technological innovation and creativity while teaching mathematics.

Penina Kamina and Nithya Iyer (2009) approve this fact: The way in which it is taught in the classrooms of basic education makes abstract contents prevail, without support in resources that allow building knowledge, going from concrete and semi-concrete representations of mathematical ideas and concepts, to synthesis activities that facilitate the abstraction and generalization of the mathematical contents of the level. The way Mathematics is taught is as important as the content. However, in order for the innovative strategies to be effective, the relationship between the teacher and student should be good, as it helps to "improve academic success" (Coe, 2018, p.29) because "students try harder, knowing someone cares about the outcomes. Students feel more comfortable seeking help when the relationship is positive and supportive" (ibid). In this way, teachers influence student's attitudes and outcomes. Students will be "willing to exert more energy learning the lesson and helping their peers" (ibid). 
All nations should keep up with the massive continuous development in all fields, and "[a]n alternative process or method of teaching has to be adopted in this fast developing world, where knowledge explosion has been taking place every day in every sphere of life. It is unreasonable to expect that spoken or written words alone can convey the volume of relevant information to the learner" (Rajkumar \& Hema, 2016, p.1), especially in teaching mathematics. It is vital to note to the fact that there are plenty of modern teaching methods that employ technology such as Smart Classrooms, Flipped Classrooms, Virtual Classrooms, Blended Learning, and mobile learning (Rajkumar \& Hema, 2016). However, the current situation of the schools that imposes various restrictions, especially in terms of resources, makes it difficult to employ them in schools. Thus, in this study, only the applicable methods and strategies are to be discussed, and the question here is: What are the innovative ways to teach mathematics that teachers have employed in Arab Israeli schools? However, teachers should be familiar in the first place with the objectives of teaching mathematics in general prior to deciding how to teach it, because setting up the objectives determines the way mathematics is to be taught.

\section{General Objectives of Teaching Mathematics}

It is generally agreed that the basic objective of teaching mathematics is, on the one hand, to prepare students for public life regardless of their work or future aspirations, and on the other hand, to give students the ability to understand mathematics itself in school or after graduation. However, there are additional objectives that should be borne in mind such as to provide students with the ability to use proper thinking methods, to apply inductive and deductive reasoning, to be contemplative and reflective, and to acquire problem solving skills.

Teachers should emphasize the importance of mathematics in public life by teaching students about the impact of mathematics on cultural development. Moreover, it is vital to provide students with the necessary skills to understand what they are studying and to discover new relationships, as well as to help them in shaping positive trends and attitudes towards mathematics. Helping students to rely on themselves in studying mathematics is also necessary, alongside with developing good habits such as accuracy, order, cooperation, mutual respect and constructive criticism, and improving mental skills and scientific innovations (Algani, 2018). 
How to achieve these goals?

Teaching mathematics is an enjoyable profession, but it is not an easy task, and it derives both its pleasure and its difficulty from the nature of mathematics and the nature of the learner and his $\backslash$ her perception of it. Like any profession, teaching requires knowledge and art. Teachers must develop themselves professionally by constantly researching the developments in mathematics and attending events such as conferences, seminars, meetings and professional training sessions in mathematics to be familiar with the appropriate knowledge as well as learning methods and strategies that make the learning environment effective. Teachers would then be able to connect mathematics with daily life and to provide students with examples and applications that are tangible so that they can interact with the teacher and interact with the material and with the learning environment, and can recognize the importance of mathematics (Algani, 2019).

Teachers should be creative in choosing examples close to the living experience of students. They should also connect mathematics with abstract thought as well as the real things in life for students to understand and love mathematics. Teaching mathematics this way facilitates students' integration into society and helps them to learn the art of thinking. If mathematics is not related to the individual in any way, learning it will be useless and merely involve memorizing for the exams. Students have many talents, and teachers should help them to use them and provide them with all the available means of illustration, especially modern ones (Algani, 2019)

Einat Heyd-Metzuyanim (2015; 2016), in her articles about the impact of procedural method and conceptual method on learning mathematics and its relationship with learning patterns and the fear of mathematics, concluded that the conceptual method leads to the development of learning mathematics among students and increases their motivation to study mathematics. She also pointed to the strong relationship between difficulties in mathematics and the traditional method of learning, which leads to a fear of mathematics and math tests which she sees as a vicious cycle: Ritual Learning $\rightarrow$ Difficulties in Mathematics $\rightarrow$ Math Anxiety $\rightarrow$ Ritual Learning. 
We have to teach our students to study mathematics as a practical subject, not as purely theoretical material. They have to memorize mathematical laws and rules only, and we should guide them to the way they apply them to be familiar with them and get used to them at an early age. Ernest (1988) suggests specifying a practical class to introduce students to some rules of mathematics in the surrounding environment through a number of activities and methods, including presenting live examples.

Kristi Coe (2018) pointed out in her article Strengthening Student Educational Outcomes: Mathematics Menu of Best Practices and Strategies that mathematics should be taught together with strategies such as magic squares and crossword games and decoding, entertainment with numbers, where students use several calculations and mathematical rules sequentially to reach a relationship between them, and make use of the maze and knowledge maps. Mathematics can be taught by playing games, as "some research has found that game-based learning is an effective way to enhance motivation and performance" (Coe, 2018, p.73). However, "Choosing which game to play depends on the instructional goal and the learning target. Games can be used both for instruction and practice. Games may also give students the opportunity to apply new learning" (ibid). The teacher must develop strategies for cooperative action and teamwork among students, because of their positive effects. By the same token, practical application of mathematical rules, and the connection of mathematics to our life, will increase motivation to learn mathematics and allow the student to understand its basic principles and applications.

Through exploring assignments and demonstration in mathematics the student understands mathematical theories in depth, overcomes the difficulties and common mistakes in mathematics, and sees the beauty of mathematics. Also. It is a good idea to exploit technology and mobile phones in the search for mathematical laws or to practice mathematical problems through games, which also develop the intellectual abilities of students and complements the educational materials. Moreover, the application of modern teaching methods is vital. The aim of using modern technological tools in education is to raise the level of the educational process as a whole, and thus to create a generation that would keep up with scientific and technological developments. Such a generation will then be capable of excelling and taking a leading role in building the nation and its various 
scientific institutions through new educational methods dependent upon modern innovative curricula with a primary focus on the student learner. Masa'adeh argues that teaching mathematics to students at different educational stages may seem difficult for teachers, students, and even parents at home.

The disparity between the educational abilities of the students and individual differences between the students, the lack of educational qualifications among the teachers, and the differences in the educational levels of the parents, causes a critical gap in teaching mathematics. All this requires reconsidering the nature of the curriculum for mathematics itself, the quality of the methods used in its explanation, and finally, the extent to which the students accept their content and achieve good results at the end of each semester (Algani, 2018). Teachers should employ technology in teaching mathematics because students love technology, and they will be more than happy to study mathematics through technological tools. There are various ideas that can be exploited, and teachers can use innovative and creative ideas to encourage students to study mathematics and most importantly understand it. Besides, "when used strategically, technology can provide students with greater access to conceptual understanding and procedural fluency" (Coe, 2018, p.37). However, it is not enough to use technology alone, as it "cannot replace effective teaching or intervention activities" (ibid). Coe also asserts that technology can provide students with additional representations of mathematical ideas, allow inquiry-based exploration, reinforce procedural learning and fluency, and provide efficient screening and diagnostic assessment data (ibid. p. 38). According to the Ministry of Education (2013; 2014; 2018) significant learning 2 occurs when students learn beyond the facts, interpret information, create connections between facts, think about the processes of their comprehension, and apply new concepts to new situations. They must think, solve problems, change their positions and opinions, develop skills and build knowledge. The Ministry of Education in Israel defined a few pedagogical

\footnotetext{
${ }^{2}$ In his book, Freedom to Learn, Carl Rogers (1973) placed significant learning in opposition to learning by rote. In his opinion, significant learning is defined as experiential learning, the opposite of rote learning which focuses on the repetition and memorization of facts that are easy to forget and easily to cram into the mind, and to which the student does not attribute any meaning. According to Rogers, significant learning occurs when the student sees what is relevant in the study material, the connection between the material to his own aims, needs and interests, and its contribution to his development. The components of significant learning, in the words of Rogers, are: personal involvement and giving the student the opportunity to innovate; the learner himself evaluates his own achievements. David Ausubel (1963) defines significant learning as the non-arbitrary and nonverbal integration of new ideas into the cognitive structure of the learner.
} 
principles, the application of which is liable to lead to significant learning. These principles are based on a constructivist paradigm. Constructivism is a theory of learning or of significant creation that proposes an explanation on the nature of knowledge and how people learn. It claims that people create or build up their understanding and new knowledge on the basis of interaction between what they already know and believe and the ideas, events and activities with which they come into contact (Richardson, 1997). The constructivist approach is based on the following premises:

Learning as an active process: In the process of learning, every student is active cognitively, physically, socially and emotionally in the construction of personal significance. Learning as a constructivist process (building up of knowledge): In the process of learning, the student builds up personal knowledge through the use of previous knowledge. The combination of earlier and new knowledge contributes to the construction of new understanding. In this process, knowledge is built up actively by the learner through an internal cognitive process at a high level that acts on stimuli from the environment (Michael, 2003), Learning as a social process: Learning occurs in the social interaction between students and their classmates and arouses internal processes of significant creation.

Authentic learning: This type of learning is based on experience in the real world. In this type of learning, materials and activities are arranged around connections "in real life" in which they are used.

Feedback from continuous evaluation: This is information that is provided by an agent (e.g. teacher, colleague, book, parent, self, experience) in relation to the aspects of performance or understanding (Hattie \& Timperley, 2007). It reflects a continuous process that provides teachers and learners with information about the development of the learning process and allows for significant feedback for the evaluation of learning during the process and after its completion in order to make decisions about teaching improvement. Application of the constructivist teaching methods: Experiential learning (practical activity) is one of the foundation stones of science and technology studies, and is essentially the interaction between physical and cognitive activity. Experiential learning is important for the buildup of knowledge, understanding and skills, for the demonstration of events and processes, for the clarification of scientific terms, and for the discoveries of learning and research. 
Coping with learners in heterogenic classes: People differ in their cognitive structures. They are differentiated by many qualities such as personality, learning style, needs and desires, cognitive abilities, ways of thinking, tendencies, habits of thought, and other variables. As a result, the role of the teacher is to expose their minds (previous knowledge, perceptions, attitudes, behavior, beliefs and positions) to a variety of experiences suitable for the construction of active knowledge.

Promoting motivation to study science and technology: An important condition for the occurrence of significant learning is interesting study and internal motivation. Among the activities that strengthen internal motivation is the cooperation of students in choosing the aims of study and the methods of evaluation; initiating experiences that arouse interest in the subject under study; clarification of the benefit value of the material studied. Another important factor in creating internal motivation is self-efficacy, thus teachers should provide challenging tasks that suit the abilities of the students and give them constructive feedback that expresses trust in their abilities. These pedagogical principles are the core components, and their significant application in the class will improve the process of teaching and learning.

\section{Prior Conditions for the Application of Learning}

In order to allow for effective learning in the classroom, a number of conditions are required relating to the perceptions and positions of those involved in the process, the educational environment, the study program, the learning-teaching process, and its evaluation. According to the document "Policy for the Advancement of Significant Learning in the Education System" (2013), the conditions that allow for the learning and advancement of students are as follows:

Perceptions and Positions: Regarding learning as a process that occurs among a group of people, teachers and students, who establish a system of relationships characterized by mutual respect, by reception and inclusion, through holding a discourse based on dialogue within the group and between groups.

Educational Environment: An emotional and positive atmosphere and a learning environment that allows for initiative and personal interpretation, autonomy in the adaption of processes for the needs of the learners. Appreciation for personal and group investment, attribution of importance to the processes as well as to the results. 
Learning: Learning is the outcome of internal motivation, interest, and curiosity, and not by external motivation such as expecting a prize or fear of punishment. The student is active in the learning process, derives significance from it, and feels that his aims are achieved. Learning builds a sense of capability, encourages achievement, and motivates new learning.

Study Program: State study programs that allow for flexibility and adaptability for the aims of the individual and society, engagement with local values and general human aspects, with problems relating to life, authentic and relevant. It is necessary to reduce the required range of material in the study programs in order to provide place for the processes of significant learning and expected achievements in relation to the individual learner, besides achievements in the sphere of knowledge. Teaching and evaluation promotes in-depth learning of the students through personal significance, interest and curiosity, through the inclusion of all the students with their various talents and abilities, the use of a variety of teaching and evaluating methods, in order to give response to their differences.

Evaluation processes are established for the sake of learning at all levels, beginning with policy evaluation and its continuous updating to the evaluation of student achievements and feedback on their learning experience for the sake of continual improvement. Appreciation of initiatives in which expression is given to qualitative processes of teaching-learning-evaluation at the level of the teacher and of the school.

Organized school environment makes it possible, through a policy of pedagogic flexibility and the empowerment of the teaching and management staff, to encourage learning at all stages, both adults and students.

Harpaz (2014) defines two types of conditions so that significant learning can occur: internal conditions and external conditions. The internal conditions are the states of consciousness that allow for significant learning; the external conditions are the characteristics of the environment that allow for and encourage internal conditions to achieve significant learning. The internal conditions are related firstly to the "inner motivation" and secondly to the "understanding of the student", to the material defined as the product of significant learning. According to Harpaz, regarding the first condition, the inner motivation for dealing with the learning activity occurs when a person performs an action that causes pleasure to him or her or because it is considered to be of value. This condition is not sufficient alone; it also requires understanding. When a person is involved in 
some assignment but does not receive some understanding of it, the learning is not significant (Harpaz, 2014b). For the external conditions, Harpaz suggests that advancement in significant learning is related to the educational environment which increases the situation of "involvement in the process of learning which creates understanding". These external conditions include a study program, a teacher, teaching methods, evaluation systems, organization of student learning, and the physical structure and equipment of the schools. Harpaz explains these conditions as follows:

The Study Program: The study program must be devoted to the authentic interests of the students. The fundamental principle of the study program which allows for significant learning is to teach meaningful subjects (Harpaz, 2012).

Teaching Methods: The fundamental principle of teaching which allows for significant learning is indirect teaching that strengthens inner motivation to be involved in active learning, the building up of knowledge and the creation of understanding.

Evaluation Systems: The fundamental principle of evaluation which allows for significant learning is rich feedback that is continuous and mediating. Rich feedback means to give the student detailed information about his achievements and failures. Continuous feedback means giving it throughout the learning process (not only after examinations). Mediating feedback means also on the product (academic research, art creation, film production, etc.) that the student creates (not only through the direct evaluation of the teacher).

Organization of Student Learning: The fundamental principle that guides learning towards becoming significant learning is giving students a choice. The school must allow for a wide range of choice for students, based on the realization that people give significance to knowledge and creativity through choosing it. The choice itself is significant, and the school should offer a variety of subjects to enable a wide choice.

Physical Structure and Equipment: Schools are physical environments that do not invite the students to remain in them, and certainly not for significant learning. New standards should be created for educational institutions and their equipment.

Ma'abrah (2018) suggests other innovative teaching methods to be applied in teaching mathematics. Starting with a computerized class, the use of explanatory methods that rely on direct teaching and information transfer should be used. The role of the teacher is to create educational situations that enable students to solve problems and to discover 
mathematical relationships. A computerized class enhances creative thinking because it requires advanced thinking abilities and capabilities such as classification, comparison, organization, and analysis. Students resort to inventing unusual methods, and prefer to use scientific thinking during computer learning through the application of the students' intellectual model, and the technological tools used in the computerized programs such as the dictionary, the calculator, the plotter, the graphic, etc. The media employed in the educational process, including audio, visual and text techniques, have a significant and effective role in the better comprehension of the material by the students through the use of different senses at the same time.

Moreover, mental calculation is an advantageous method to apply. It is manifested in the solving of mathematical problems accurately, correctly, and quickly without the need for the student to use pen, paper, or calculator. Mental calculation is one of the most important mathematical skills that are useful to students, especially in the elementary stages. It increases students' confidence and prepares them to complete their course without obstacles or difficulties. Several countries, including the United States of America and Jordan, have promoted this skill by recommending that it be provided to students in schools.

Ma'abrah also recommends that teachers should consider presenting the study material in sophisticated and innovative ways, for example in using cameras, data projectors or video films as tools to explain the lesson in a simple way by audio and visual means at the same time; children are the most responsive to this method. The verbal method alone is not enough to convey the information in the desired form; when synchronizing the verbal method with the visual one, it will reach the students in a simpler way, leading to a deeper entrenchment in their minds. In addition, teachers should consider employing the connecting method, as memory is a network of cells that helps students understand terms and concepts. Thus, when presenting any information, it must be linked to something real, or concepts already explained before, and the teacher should be aware of the extent of interaction of students, and choose the appropriate method for each of them.

Concentration should be on teaching the strategies, skills, and methods of thinking that are needed to solve any equation correctly, which creates independent students who rely on themselves. Likewise, classroom discussion and dialogue are of vital importance; that is achieved via open questions, interviewing students until the right answer is reached and the desired ideas are discovered, whether through critical thinking or yes/no questions. 
Thus, "consistently engaging students in these routines can change student's dispositions about mathematics" (Coe, 2018, p.34). In addition, Ma'abrah claims that providing swift corrections for classwork is essential; when students are asked to solve a worksheet or an assignment in mathematics, it must be corrected within a short period of time with the proper answers and comments. Collective learning is also important, which is manifested in the students' interaction with each other, such as asking a question in class, with each student writing down his/her answer, and then discussing these answers with each other. Besides, offering moral support to students is critical, which is achieved by encouraging phrases which raises their morale at the same time. Classroom conversation and discussion is an essential means through which students' difficulties and common mistakes can be discovered.

\section{Method}

Life stories expose the significance and subjective interpretation given to his life by an individual, and to certain events that occur during the course of his life (Plummer, 1995). In this research work I am trying to expose the teaching methods used by teachers of mathematics in Arab schools in Israel, and to describe the emotional state of 48 pupils of the Arab sector in Israel. Raising their personal stories is intended as information that can be used as a parameter for the effective improvement of their experience in the school. Location of the participants was carried out through personal acquaintance with their teachers and parents who helped in finding additional research participants.

The collection of research data was done through semi-structured interviews conducted with each of the participants alone in a study room in the school. Each interview extended from half an hour to fifty minutes. The appointed time of the interview was fixed in advance, and at the beginning of the meeting each pupil received brief information about the subject of the interview and was asked to agree to its recording, with the explanation that the research was anonymous and confidential. Agreement was given verbally by the pupils, parents and teachers. The personal questions made use of the narrative interview technique that allowed for the presentation of stories and film scripts of a mathematics lesson that can explain the experience of pupils in the transition from the intermediate to the high school level. 
Participants in the research included 48 Arab pupils during their first term in different school stages (primary stage, middle stage, and high stage). All of them are of the different socio-economic background. According to the report of their teachers, their achievement in mathematics ranged in level from low to high (all the names of the interviewees are fictitious).

\section{Findings}

In this section the findings of the interviews are presented in an attempt to understand the methods the teachers applied in their mathematics lessons. The research findings indicate five categories: application of constructive learning principles, use of a variety of teaching and evaluating methods, differential teaching, use of digital tools and applications, and evaluation for the sake of learning. In order to identify the teaching practices that promote learning, the interviews in this research contained a central question: What, in your opinion, are the types of teaching practices that promote significant learning which the teacher has applied in teaching the subject you are studying? Analysis of the students' answers to the above question was made according to a previously described qualitative analysis. The categories were constructed from an analysis of the content of the interviews with the students according to key words. The content analysis which was collected from the interviews and classified into categories was based on the professional literature. The findings of the question were compared to the literature background and to other research studies.

\section{Findings of the Interview Question}

The content was received in answers to the question: What in your opinion are the types of teaching practices that promote significant learning that the teacher applies in teaching mathematics? This was based on a number of guiding questions. The categories that were received after the content analysis present the teaching practices that promote significant learning accompanied by examples.

\section{Application of Constructive Learning Principles}

Most of the students reported the non-application of the teaching practices based on the principles of constructive learning. The students gave examples that showed the non-use of the constructivist principles as described below: 
When Sam was asked, he replied that: "The teacher did not co-opt the students in the independent construction of knowledge through investigation". Yusuf says that: "She does not give the student an opportunity to take a significant part in the learning process in an active manner such as participating in projects". Dani says that: "The teacher does not explain to the students why they are learning a certain subject, for example, how is it connected to other subjects in daily life or in future professions, and give examples from our real world". Tom says that: "The students are not working on assignments in groups".

This finding was not supported by the document of the Ministry of Education (2018) in which a number of pedagogical principles were defined for the promotion of significant learning. One of these principles was the constructivist approach in which the learner builds up his knowledge by himself through the use of active learning, group work, and relating to relevant components. In addition, while he is learning, the student reflects upon his own process of learning.

Use of a Variety of Teaching and Evaluating Methods

Some of the students noted the non-use of various teaching methods in order to promote learning. The students answered as follows:

When Avi was asked, he replied that: "The teacher does not bring examples to the classroom and only draws on the board or solves problems". Sara says that: "There are no concrete mathematical presentations in the lessons". Sami says that: "The teacher does not mark homework assignments". Hadi says that: "The teachers do not mark homework assignments in a thorough manner".

This finding was not supported by Harpaz (2014) who claimed that the fundamental principles of teaching which allows for learning is the use of indirect teaching methods such as mentioned above which increase active involvement in the building up of knowledge and the creation of understanding by the student himself.

\section{Differential Teaching}

Differential teaching is teaching that is adapted to the personal characteristics and unique abilities of the student. It is also one of the procedures on which the students reported. The lack of concern for differential teaching was expressed in the following sentences: 
When Tome was asked, he replied that: "I feel that the lessons on mathematics do not make sense to me, I do not understand mathematics, and the teacher does not pay attention to me". Amer says that: "Lessons in mathematics are difficult; the teacher begins the lesson by solving examples and no one understands what he is doing". One of the students noted that (Badre): "I am trying to understand the study material at home, and my parents help me to understand it".

According to Keller (1983), the approach of adapting teaching to the characteristics and abilities of the students is one of the ways that makes learning more relevant to the student. Relevance in learning is one of the three main principles of significant learning that was declared in the document of the Ministry of Education (2018).

Use of Digital Tools and Applications:

A number of students emphasized that the teachers do not use digital tools in mathematics lessons. One of the students said:

When Omar was asked, he replied that: "The teacher does not even activate the computer in the classroom even though there is a computer and a screen in it during the lesson". Another student Taha stated that: "The teacher sometimes uses the computerized display but she reads the formulas from it and we do not understand anything".

This finding was not supported by the professional literature which stresses the need for using technological tools for promoting significant learning. Ashburn and Floden (2006), in their book Meaningful Learning Using Technology, emphasize that technology acts for the learners like an intellectual partner who helps them to advance in thinking, learning and understanding the world in which we live. Learning with the help of technology will promote significant learning if it is based on the involvement of the learners in the construction of knowledge; on dialogue; on self-expression of the knowledge acquired; on the use of reflective thought. All this is achieved through the processes of learning that include, among other things, visualization.

Evaluation for the Sake of Learning:

Some of the students emphasized that the teachers use evaluation only in the examinations at the end of the semester. Examples from the answers of students who stress this importance are as follows:

When Alex was asked, he replied that: "The teacher always gives homework and does not mark our answers, and if he marks them he does not say why they are not correct. He does not give us examinations to know if we know the material or not". Another student Ana stated that: 
"The teacher always asks questions during the lesson, but if we do not answer correctly he becomes angry and does not like insults".

This finding is not supported by Harpaz (2014) who claims that the fundamental principle of evaluation allows for significant learning through rich feedback, which is continuous and mediating. It is rich because it gives the student detailed information about his achievements and failures; it is continuous because it is done throughout the learning process (not only in examinations); it is mediating because it is also derived from the product that the student creates (not only from the direct evaluation of the teacher). The document of the Ministry of Education (2018) also emphasizes the importance of continuous evaluation which gives teachers and learners information about the development of the learning process and allows for significant feedback in evaluating learning during its process and afterwards in order to make decisions on the improvement of teaching.

\section{Conclusions}

This study highlights the strategies that are used in schools to teach mathematics. It stresses some innovative strategies to teach mathematics and examines whether they are applied in schools or not. The strategies are divided into five subcategories. The results of the interview revealed the low applicability of the included strategies in classrooms. The study concluded that more attention should be paid to the strategies employed in teaching mathematics, and technology. Also, innovative and modern strategies should be considered in schools because they proved advantageous in teaching mathematics. Moreover, this study concludes that the load of mathematics curricula is to be reconsidered, and the priority should be students understanding of mathematics via exploiting various means and employing modern technological innovative strategies in teaching mathematics.

\section{References}

Algani, Y., M. \& Eshan, J. (2019). Reasons and suggested solutions for low-level academic achievement in mathematics. International e-Journal of Educational Studies (IEJES), 6 (3), 142-151. DOI: 10.31458/iejes.571751.

Algani, Y. (2018). Applying creative skills in teaching math at the primary school stage. Journal of International Economy and Business, 6, 26-33.

Ashburn, E.A. \& Floden, R.E. (2006). Meaningful learning using technology: what educators need to know and do? New York: Teachers College Press. 
Ausuble, D. P. (1963). The psychology of meaningful verbal learning. New York: Grune and Stratton.

Coe, Kristi (2018). Strengthening student educational outcomes: mathematics menu of best practices and strategies. OSPI, RCW 28A.165 \& 28A.655.235.

Entwistle, N. (2005). Contrasting perspectives on learning. In: F. Marton, D. Hounsell, N. J. Entwistle (eds.), The experience of learning: Implications for teaching and studying in higher education (pp. 106-125). Edinburgh: University of Edinburgh.

Ernest, P. (1988). The impact of beliefs on the teaching of mathematics. $6^{\text {th }}$ International Congress of Mathematical Education, Budapest, August.

Harpaz, Y. (2012). Why theatre: from a profession to a field of meaning. Education. PO (5), $52-55$.

Harpaz, Y. (2014a). Learning what can do? avnei derech. Avni Rosha Institute.

Harpaz, Y. (2014b). Conditions for meaningful learning. Hed-Hahinoukh, 20(4), 40-45 (Hebrew).

Hattie, J.A.C., \& Timperley, H. (2006). The Power of feedback. Review of Educational Research, 77(1), 81-112.

Heyd-Metzuyanim, E. (2015). Vicious cycles of identifying and mathematizing: a case study of the development of mathematical failure. Educational Studies in Mathematics, 89(1), 504-549.

Heyd-Metzuyanim, E., \& Graven M. (2016). Between people-pleasing and mathematizing: South African learners' struggle for numeracy. Educational Studies in Mathematics, 91(3), 349-373.

Israel Ministry of Education (2013). Policy for promoting meaningful learning in the educational system, Jerusalem- Israel (Hebrew).

Israel Ministry of Education (2014). Something good is happening now: milestones in meaningful learning, Jerusalem- Israel.

Israel Ministry of Education (2018). Curriculum of science and technology, Jerusalem- Israel (Hebrew).

Kamina, Penina, Iyer, Nithya N., (2009). "From concrete to abstract: teaching for transfer of learning when using manipulatives" NERA Conference Proceedings.

Keller, J. M. (1983). Motivational design of instruction. In: C. M. Reigeluth (ed.), Instructional-design theories and models: an overview of their current status. Hillsdale, NJ: Lawrence Erlbaum Associates.

Ma'abrah, T. (2018). Innovative ways to teach mathematics, Alnjah University, NablisPalstain (Arabic).

Masa'adeh, M. (2016). Modern teaching methods of mathematics, Alnjah University, NablisPalstain (Arabic).

Michael, J. A. \& Modell, H. L. (2003). Active learning in secondary and college science classrooms. Mahwah, NJ: Lawrence Erlbaum.

Plunner, K., (1995). Telling sexual stories: power change, and social worlds. New York: Routledge. 
Rajkumar, R. \& Hema, G. (2016). Modern mathematics classrooms: facilitating innovative teaching methods and learning strategies for 21st century learners. Edusearch, 7, 70-74.

RAMA (2018). Evaluation of the systemic plan "meaningful learning": perceptions of students, teachers and principals in the years 2014-2017, Jerusalem- Israel (Hebrew).

Ricardson, V. (1997). Constructivist teacher education. London: Falmer Press.

Rogers. C. R. (1973). Freedom to learn. Tel Aviv: Poalim Library (Hebrew). 